\title{
1 Rufous Common Cuckoo chicks are not always female
}

Jaroslav Koleček (https://orcid.org/0000-0003-1069-6593), ${ }^{1}{ }^{*}$ Michal Šulc, ${ }^{1}$ Radka Piálková, ${ }^{1,2}$ Jolyon Troscianko, ${ }^{3}$ Milica Požgayová, ${ }^{1}$ Marcel Honza ${ }^{1}$, Petr Procházka ${ }^{1}$ (https://orcid.org/0000-0001-93854547)

${ }^{1}$ The Czech Academy of Sciences, Institute of Vertebrate Biology, Květná 8, CZ-603 65 Brno, Czech Republic

${ }^{2}$ Faculty of Natural Sciences, University of South Bohemia, Branišovská 31, CZ-370 05 České Budějovice, Czech Republic

${ }^{3}$ Centre for Ecology \& Conservation, College of Life \& Environmental Sciences, University of Exeter, Penryn Campus, Penryn, Cornwall, TR10 9FE, UK

*Corresponding author.

Email: j.kolecek@gmail.com

Phone: +420605552978

\section{Abstract}

The Common Cuckoo shows two adult plumage morphs - adult male plumage is grey and adult females are either grey or, less frequently, rufous. The situation is less clear in juveniles, as both sexes exhibit variable proportions of grey and rufous colour. We thus describe the patterns related to sex-specific plumage colour variation in a central European Cuckoo population. We genetically determined sex of 91 Cuckoo chicks and using visual classification of photographs we scored juvenile plumage colouration of individual chicks into five classes based upon the increasing proportion of feathers with rufous colour. To verify these scores, we sampled chick feathers and quantified the proportion of rufous colour on individual feathers by digital image analysis. We found that juvenile females had a higher proportion of rufous colour on feathers than juvenile males. However, the difference was marginally non-significant based on visual inspection alone, and some male chicks even showed intensively rufous plumage like those of juvenile females. In contrast, we captured only grey adult males $(\mathrm{N}=37$ ) while 5 out of 20 adult females were rufous. The rufous colour of Cuckoo feathers considerably differed from the grey colour and the difference was larger in adults than in juveniles. We show that chicks, unlike a dult females, cannot be visually assigned to either of the adult morphs. Therefore, we encourage further investigation of Cuckoo plumage colouration across the species range and to examine the process of plumage maturation. A detailed genetic a nalysis is necessary to understand the origin of Cuckoo feather colouration.

Keywords: avian vision; colour dimorphism; Cuculus canorus; molecular analysis; plumage colouration; spectral reflectance

\section{Introduction}

Colour synthesis is a very complex process that can be affected both genetically and environmentally (Galván and Solano 2016) and that may result in the coexistence of two (i.e. dimorphism, Bond 2007) or more distinct colour forms in one interbreeding animal population (Huxley 1955). This phenomenon, known as intraspecific colour polymorphism, has been observed across many vertebrate species (Galeotti et al. 2003; Gray and McKinnon 2007) and has provided key models for studies in evolutionary biology including sexual selection, speciation, and mimicry (McKinnon and Pierotti 2010). In birds, the most common plumage pigment, melanin, occurs in two forms eumelanin and pheomelanin (Hill and McGraw 2006). The proportion of eumelanin and pheomelanin determines bird plumage colouration - lighter (yellow to red) phenotypes originate from the 
increased deposition of pheomelanin, while darker ones (brown to black) result from the increased deposition of eumelanin (McGraw et al. 2005; Hill and McGraw 2006).

Excluding sexual dichromatism, seasonal change and age differences, about 334 (3.5\%) of all world bird species exhibit plumage colour polymorphism, including 241 species with only two colour plumage morphs (Galeotti et al. 2003). The colour polymorphism occurs most frequently in Strigiformes (owls and nightjars - 33.5\% species), Cuculiformes (11.9\%) and Galliformes $(9.5 \%$, Galeotti et al. 2003). Colour polymorphism has been mainly explored in adult birds, but far less attention has been paid to such a variation in juveniles. In some species, plumage morphs do not change with age and moults (e.g. Ruff Philomachus pugnax and Buzzard Buteo buteo; Lank et al. 1995; Kappers et al. 2017) whereas in others, they differ between juveniles and adults, such as in many raptors (Ferguson-Lees and Christie 2001; Roulin 2004) or cuckoos (Voipio 1953; Cramp 1985).

Obligatory parasitic Common Cuckoos Cuculus canorus (hereafter Cuckoos) exhibit two typical colour morphs. Adult males are grey, and females either resemble the males (some with rufous tinge on the upper breast and neck, Noh et al. 2016), or occur in a rufous morph (Voipio 1953; Payne 1967). Female polymorphism is also known in other parasitic cuckoos, but is absent in non-parasitic ones (Payne 1967). In coevolutionary arms races between cuckoos and their hosts, variable plumage colour may have evolved as a result of apostatic selection (Payne 1967) or as a counteradaptation to resemble avian predators - unknown or predator-like plumage can reduce the chance of being recognized and attacked by the hosts (Davies and Welbergen 2008; Welbergen and Davies 2011). Alternatively, the females may simply keep their plumage to adulthood as paedomorphic retention (neoteny, Trnka et al. 2015). Nevertheless, the proportions of morphs differ substantially between sites; from those where the rufous females are almost entirely absent (Thorogood and Davies 2012) to sites where they are common (Honza et al. 2006; Table 1).

Cuckoo fledglings exhibit far more varied combinations of grey and rufous colour than adults, to the point where the border between the morphs is hardly detectable (Cramp 1985). So far, only Voipio (1953) attempted to evaluate the plumage polymorphism in juvenile Cuckoos; however his study was restricted to a relatively small number of museum specimens. Contrary to Cramp (1985), Voipio (1953) distinguished three juvenile plumage types - grey-brown and rufous type for both sexes and red phase which should occur in females only. However, his material did not contain any specimen of such a red phase and the variability in the fledgling colouration has never been classified in detail. Moreover, it remains unknown whether the fledglings resembling the adult rufous morph are always females.

Here, we describe variation in the proportion of grey and rufous plumage colour in a central European Cuckoo population. We used both subjective assessments and objective digital imaging for colour categorisation, and also compare the plumage colouration between males and females in juveniles and adults. In light of the prior research mentioned above, we predict that the rufous colouration will be more frequent in females than in males. Finally, we also discuss a possible genetic background of Cuckoo plumage colouration.

\section{Methods}

Fieldwork

The study was carried out from April to July 2016 and 2017 (with so me adults recaptured in 2018) in the fishpond area between Mutěnice $\left(48^{\circ} 54^{\prime} \mathrm{N}, 17^{\circ} 02^{\prime} \mathrm{E}\right)$ and Lužice $\left(48^{\circ} 50^{\prime} \mathrm{N}, 17^{\circ} 04^{\prime} \mathrm{E}\right)$ in southeastern part of the Czech Republic. To find active nests with Cuckoo chicks, we systematically searched littoral vegetation with numerous territories of Eurasian Reed Warblers Acrocephalus scirpaceus, Great Reed Warblers Acroce phalus arundinaceus and Sedge Warblers Acrocephalus 
schoenobaenus, and also occasionally checked the adjacent sites preferred by Marsh Warblers Acrocephalus palustris. In April and May of the same years, we also mist-netted 57 adult Cuckoos from the same study site.

\section{Sex determination}

When the chicks were at least 6 days old, a small amo unt of blood (5-25 $\mu$ l) was collected by tarsal venipuncture and stored in $100 \mu \mathrm{l}$ of $96 \%$ ethanol. Chick sex was later determined in the laboratory by amplifying a part of the $\mathrm{W}$-linked chromo-helicase-DNA binding gene CHD-W (unique to females) and a part of its homologue, the CHD-Z gene, linked to the Z chromosome (occurring in both sexes, Griffiths et al. 1998). After DNA extraction, the avian sex primers P2 and P8 (Griffiths et al. 1998) were used in $10 \mu \mathrm{I}$ PCR reactions (for details of PCR conditions see Abraham et al. 2015). The PCR products were separated by electrophoresis for $45-60 \mathrm{~min}$ at $7-10 \mathrm{~V} / \mathrm{cm}$ using $3 \%$ agarose gels stained with SYBR ${ }^{\circ}$ Safe (Life Technologies, Invitrogen, Carlsbad, CA). Heteroga metic females were characterised by a two-band profile ( 350 and $\sim 400 \mathrm{bp})$, while homogametic males by only a single band ( $400 \mathrm{bp}$ ). The sex of adults was determined genetically following the same procedure as in juveniles.

\section{Classification of plumage colouration}

To describe and catego rize plumage colouration, we photographed 77 out of the 91 Cuckoo chicks (N $=43$ originating from the nests of the Eurasian Reed Warbler, $N=32$ from Great Reed Warblers and 1 each from Marsh and Sedge Warblers) at the age between 9 and 18 days (median $=14$ ). We distinguished five plumage colour classes based upon the proportion of rufous colour present on feathers on a Cuckoo back and upon the shape and size of rufous spots and stripes on individual feathers on the following semi-continuous ordinal scale: 1) Grey - rufous colour missing or present on $<5 \%$ extent of contour feathers on less than one half of the back, individual rufous spots smudgy and disjunct. 2) Medium grey - rufous colour on 5-10\% extent of contour feathers on the major part of the back. Individual rufous spots thin, their length exceeds the width. The spots usually do not form stripes crossing shafts of the feathers. 3 ) Intermediate - similar to 2, but the disjunct rufous spots are thicker, their length usually equals width. The spots are present on $11-20 \%$ extent of almost all back feathers. Sometimes, the spots may cross the whole feather, but in such case their width is similar to 2. 4) Medium rufous - rufous on $21-40 \%$ extent of all back feathers, rufous stripes lead across the feather and their width is similar to 3 . Some stripes may be interrupted, but the gap thinner than one third of stripe length. 5) Rufous - rufous on $>40 \%$ extent of all back feathers, uninterrupted stripes cross the feathers and their width is larger than in 3 and 4 (see Electronic Supplementary Material, Fig. S1 for sample photographs representing individual classes). These classes did not coincide with the plumage morphs in Voipio (1953; i.e. grey-brown, rufous and red) and did not depend on age when the chicks were photographed (linear regression: slope $=0.066 \pm$ $\left.0.068 \mathrm{SE}, F_{1,75}=0.94, P=0.334\right)$.

Based on this five-degree classification, one image of each chick was independently assigned to one plumage colour class by the authors (except for J. T.) and Vojtěch Brlík, Radka Poláková, Peter Samaš and Kateřina Sosnovcová (Electronic Supplementary Material, Table S1), who all have field experience with Cuckoo chicks. Each of the ten judges was blind to the nestling sex. Using R (R Core Team 2016) we calculated interclass correlation coefficient (ICC; package 'irr', Gamer et al. 2012) for testing similarity in scores given by individual judges and thus the reliability of the classification. The scores given by individual judges to each chick were highly consistent $\left(I C C=0.883, F_{76,693}=76.6, P<<\right.$ 0.001 , Electronic Supplementary Material, Table S1). Finally, we averaged the obtained plumage colour scores.

We distinguished between grey and rufous colour morph in the captured a dult Cuckoos. The grey morph is typical of predominantly grey upper parts without contrasting rufous colouration 
(Electronic Supplementary Material, Fig. S2). The rufous morph resembles the (v) rufous juvenile plumage colour class - i.e. individuals have marked rufous stripes on the upper part of their body (Voipio 1953; Electronic Supplementary Material, Fig. S2). As the differences between the adult morphs are clear-cut, we did not apply any detailed evaluation of feathers or images of plumage colouration.

\section{Analysis of feather colouration}

Because the human classification of chick plumage coloration may be subjective, we also performed a digital analysis of feather colouration and correlated the results obtained from both approaches. We collected feathers from the upper back belonging to 87 out of the 91 Cuckoo chicks ( $N=50$ chicks found in the nests of Eurasian Reed Warblers, 35 in Great Reed Warblers and 1 each in Marsh and Sedge Warblers) at ages of between 11 and 23 days (median $=14$ ). Feathers were scanned using a flatbed scanner (HP Color LaserJet Pro MFP M176n, resolution: $14028 \times 10200 ; 1200$ dpi). Because we expected a certain degree of variability in feather colouration, we always scanned up to six feathers from the same individual, performed further analyses for each feather separately and then averaged the measurements to obtain single values for each individual. Feathers were fastened by a strip of adhesive tape to a white sheet of paper and scanned with a scale. Colour measurements of the feathers were made using ImageJ version 1.51k (ImageJ 2018), by selecting four regions of interest: dark grey feather sections, rufous feather sections, light grey down feather sections and the white background of paper. In total, the mean RGB values of 442 feather sections were measured to create a model training database. These values were then used to create a neural-net multinomial logistic regression mo del in $\mathrm{R}$ (version 3.4.2), using the ' $\mathrm{nnet}$ ' package (version 7.3-12, Venables and Ripley 2002), where feather section types (dark grey, rufous, light grey or background) were the dependent and the RGB values the independent variables. This model was able to classify $99.77 \%$ of the 442 training measurements correctly. The resulting model was converted into a JAVA ImageJ plugin script, which transformed all scanned feather images into the four categories based on pixel colour and reported the number of pixels in each group. The proportion of rufous colour on each feather was calculated as number of pixels denoting rufous colour divided by number of pixels denoting rufous and dark grey colour of the feather (see Electronic Supplementary Material, Fig. S3). This proportion did not depend on the age of the chicks (linear regression: slope $=-0.763 \pm 0.801 \mathrm{SE}$, $F_{1,85}=0.91, P=0.343$ ).

In addition, we measured spectral reflectance $(300$ to $700 \mathrm{~nm}$ ) of the feathers from eight chicks (two females, six males) and two adult rufous females. We collected three feathers from the upper back of each individual. The feathers from each individual were stacked upon each other and attached to a black sheet of paper with adhesive tape. We used a reflectance spectrophotometer (USB 2000, Ocean Optics, Dunedin, FL), a deuterium and halogen light source (DT-Mini-GS, Ocean Optics), and a quartz optic fibre (QR400-7-UV/VIS-BX, Ocean Optics). The measurements were relative to a standard white reference (WS-1, Ocean Optics) and to darkness. Reference and dark calibration were made prior to the measurement. MŠ performed all measurements under standard light conditions, at the same angle $\left(90^{\circ}\right)$ and same distance from the feather sample. The reflectance of both grey and rufous colours was measured in the central part of the feather (Electronic Supplementary Material, Fig. S3). We performed and averaged three measurements of the grey part and other three measures of the rufous part of the feather sample per each individual. The average values of the grey and rufous from each individual were then averaged to obtain the overall mean reflectance spectra for each colour in juveniles and adults sepa rately.

\section{Results}


Ranges of mean plumage colour scores were similar between juvenile Cuckoo males (mean score $=$ $2.29 \pm 0.16 \mathrm{SE}$, range: $1.0-4.5)$ and females (2.82 $\pm 0.20 \mathrm{SE}, 1.0-5.0$; Electronic Supplementary Material, Table S1), both scoring around the middle of the scale. Females were marginally nonsignificantly more rufous than males (Mann-Whitney-Wilcoxon $W=917, P=0.068$; Fig. 1a). This human classification of chick plumage colouration tightly positively correlated with the proportion of rufous colour measured from individual feathers using image a nalysis $\left(r_{s}=0.87, P<0.001 ; n=73\right)$. The proportion was significantly higher in juvenile females $(0.7-46.0 \%$, mean $=16.81 \% \pm 2.00 \mathrm{SE}, n=$ 38) than in juvenile males $(0.5-38.2 \%$, mean $=11.07 \% \pm 1.42 \mathrm{SE}, n=49$; Mann-Whitney-Wilcoxon $W$ $=1197, P=0.023$; Fig. $1 \mathrm{~b}$ ).

Out of 57 captured adult Cuckoos, all 37 males belonged to the grey morph, while 15 out of 20 females were grey and 5 rufous. The rufous colour of Cuckoo back feathers considerably differed from the grey colour (Fig. 2) and the difference seemed to be larger in adults than in juveniles (Fig. 2).

\section{Discussion}

Our study presents detailed data on colour variation of Cuckoo chicks and provides a simple human using image analysis. Both the digital image analysis as well as visual classification revealed that most Cuckoo chicks exhibited grey or intermediate plumage colouration, but the two distinct colour morphs present in Cuckoo adults are hardly distinguishable in chicks. Regardless of the method used, female chicks were generally more rufous than males. Surprisingly, the intersexual differences in plumage colouration and in the proportion of rufous colour on feathers were quite small in chicks and some males had rather intensely rufous plumage. Yet, such male colouration was not observed in adult Cuckoos where the rufous plumage was recorded only in abo ut a quarter of females mistnetted in our study area, which is similar to the proportion of female chicks belonging to the medium rufous and rufous plumage colour classes.

We developed a five-degree classification which covers the large variability of chick plumage colouration. Unlike Voipio (1953), who first attempted to explain patterns in Cuckoo plumage colouration, we doubt that it is possible to reliably visually distinguish any colour plumage morphs in Cuckoo chicks. Instead, individual chicks that we examined exhibited a continuous va riability of rufous colour in individual feathers as well as in their plumage (see also Cramp 1985). Hypothetically, the two 'most rufous' chick plumage colour classes 4 and 5 might roughly correspond with the rufous morph in adult females (e.g. due to prevailing uninterrupted rufous stripes). In which case, around $25 \%$ of female chicks would be rufous, which corresponds with the proportion of adult rufous females in the study population. In contrast, $15 \%$ of juvenile males and no adult males would be rufous. Thus while we may possibly see a link between the colouration of juvenile and adult females, the process of male plumage maturation is probably different.

Despite Voipio's (1953) statement that the plumage of juvenile males should not be intensely rufous, together with 'textbook' images claiming that rufous Cuckoo chicks are females (but see Mann 2014), the male chicks which we investigated fell into all plumage colour classes, and some the reby resembled even the most rufous females. This striking finding could suggest that some male chicks may occasionally retain rufous colour until adulthood (Ringleben 1958; Becker 1989; Busche 2003). Although the proportion of adult rufous females in our study population agrees with their distribution across Europe (see Table 1 for summary), we did not record any adult rufous males. In Germany, a dult rufous Cuckoo males should represent about 1\% of rufous Cuckoos (Busche 2003) but the mechanisms underlying the origin of this male 'morph' remain unknown and may differ from those in females. We may only speculate that such males could perhaps suffer from moult disorder 
or eumelanin production dysfunction. Moreover, previous evidence comes only from visual observations where the sex was not genetically determined. Therefore, it is possible that even some (rufous) females may rarely exhibit male calls and thus may resemble males (Odom et al. 2014). Evidence will probably remain sporadic, because the most reliable approach - ringing projects targeting the Cuckoo - are scarce and commonly used bird monitoring schemes do not take the Cuckoo morphs into account (e.g. Gregory et al. 2007). Consequently, most observers presumably do not pay much attention to the colour and sex of individual Cuckoos.

In birds, plumage colour morphs are known to be genetically determined (Galeotti et al. 2003) and mostly follow Mendelian segregation of several alleles at a limited number of loci (Sinervo and Zamudio 2001; Roulin 2004; McKinnon and Pierotti 2010; Wellenreuther et al. 2014). Plumage polymorphism may also be governed by few genes of major effect (e.g. a supergene sensu Küpper et al. 2016). Cuckoo colour morphs have been known for a long time (Voipio 1953), but the underlying genetic mechanisms remain unknown. A high proportion of the juvenile Cuckoos within the intermediate plumage colour class (possibly heterozygous) as well as a lower proportion of grey and namely rufous Cuckoos (possibly ho mozygous) may suggest that Cuckoo plumage colouration follows Mendelian inheritance as well (see also Voipio 1953). However, the differences in colouration between most juvenile males and females are weak. Thus we cannot rule out the possibility that interactions among loci or between genes (e.g. non-allelic genes, duplicate genes with cumulative effects with do minance or epistatic genes - recessive or dominant epistasis) or even more complex mechanisms contribute the variation in plumage colouration (Sinervo and Svensson 2002; Carlborg and Haley 2004; Phillips 2008; Rankin et al. 2016). Rufous colouration of adult females and juveniles may further indicate that sex-specific endocrine cascades during development or frequencydependent selection instead of the complex genetic interactions could determine the sexual differences (Rankin et al. 2016).

We have only a necdotal evidence about the plumage colouration in different stages of Cuckoo life a rufous female chick found at the study site in 2016 (plumage colour score $=5.0$ ) was retrapped there in spring as a rufous adult female in 2017 and also stayed rufous in 2018, when retrapped there again. Similarly, a male recaptured at the study site in 2018 was a grey chick (score $=1.9$ ) ringed there in 2017 (Electronic Supplementary Material, Fig. S2). A possible link between the juvenile and adult Cuckoo colouration was introduced by Trnka et al. (2015) who suggested that the occurrence of the rufous female morph in adults may be caused by neoteny (paedomorphosis), i.e. by the retention of juvenile colouration in the adulthood (Gould 1977; Mc Kinney and McNamara 1991). Such heterochronic plumage ontogeny, in which adult individuals retain juvenile like plumage, has been observed in other bird species (Foster 1987; Berggren et al. 2004). However, individual development of Cuckoo plumage remains unknown.

A potential explanation for the evolution of rufous plumage colouration in juvenile Cuckoos concerns the relation between camo uflage and the risk of predation (see Wauters et al. 2004). This theory is supported by evidence that, individuals of bird species with a greater proportion of rufous plumage colour have higher relative annual survival rates (Galván et al. 2012; Galván and Møller 2013) except under adverse conditions (Karell et al. 2011). Unfortunately, we do not have enough data to test these assumptions and they remain a perspective for future research.

The Cuckoo is well-suited for the study of plumage colouration. Our classification as well as the image analysis showed that juvenile colouration of both sexes was similar. Namely, not only juvenile females, but also juvenile males may exhibit rufous colouration, which, in contrast to adult females, was not observed in adult males. However, the process of colour change during ontogeny, as well as its underlying molecular mechanisms, remains unknown. We thus encourage investigating Cuckoo plumage colouration across the species range in order to compare the patterns and processes of phenotype and genotype variation among populations. Future studies should also test for correlations with behavioural, physiological and fitness traits and explore changes in plumage 
colouration in particular regions over time. Such research may elucidate whether juvenile and adult colouration differs in response to factors that determine the changes in population size (Roulin 2004), and would provide valuable insights into the evolutionary history of colour dimorphism in avian brood parasites, and in a nimals in general.

\section{Acknowledgements}

We would like to thank Miroslav Čapek, Václav Jelínek, Lukáš Kulísek, Boris Prudík, Gabriela Štětková and Klára Žabková for help with fieldwork, Vojtěch Brlík, Radka Poláková, Peter Samaš and Kateřina Sosnovcová for assistance in the field as well as for scoring the Cuckoo chicks and Marie Kotasová Adámková for helpful advice on the measurements of spectral reflectance. We are also grateful to two anonymous reviewers for their valuable comments, Petr Suvorov and Veronika Štočková for their support and to the managers of the Hodonín Fish Farm for the permission to conduct the fieldwork on their grounds. This study was supported by the Czech Science Foundation (project 1712262S) and by the Institutional Research Plan (RVO: 68081766).

\section{Compliance with ethical standards}

All applicable international, national, and institutional guidelines for the care and use of animals were followed (Czech permit MUHOCJ 34437/2014 OŽP). The authors declare that they have no competing interests.

\section{References}

Abraham M, Požgayová M, Procházka P, Piálková R, Honza, M (2015) Is there a sex-specific difference between parasitic chicks in begging behaviour? J Ethol 33:151-158

Arbeitskreis Göttinger Ornithologen (2007) Der Kuckuck in Süd-Niedersachsen - ein Schlawiner mit Problemen. http://www.ornithologie-goettingen.de/?p=137 (accessed 12 April 2018)

Becker L, Dankhoff S (1973) Der Kuckuck (Cuculus canorus canorus L.) in der Oberlausitz. Abhandlungen und Berichte des Naturkundemuseums Görlitz 48: XIII/1-XIII/9

Becker P (1989) Ein rotbraunes Männchen des Kuckucks (Cuculus canorus) bei Gronau/Leine. Beiträge zur Naturkunde Niedersachsens 42:158

Berggren Å, Armstrong DP, Lewis RM (2004) Delayed plumage maturation increases overwinter survival in North Island robins. Proc R Soc B 271:2123-2130

Berndt RK, Koop B, Struwe-Juhl B (2003) Vogelwelt Schleswig-Holsteins, Bd. 5, Brutvogelatlas. 2. Auflage. Wachholtz, Neumünster

Bond $A B$ (2007) The evolution of color polymorphism: crypticity, searching images, and apostatic selection. Ann Rev Ecol Evol Syst 38:489-514

Bračko F (2017) The occurrence of rufous-morph Cuckoo Cuculus canorus females in NE Slovenia. Acrocephalus 37:61-62

Brichetti P, Fracasso G (2006) Ornitologica italiana. Identificazione, distribuzione, consistenza e movimenti degli ucceli italiani. Bd. 3. Bologna: Perdisa 
Busche G (2003) Zur Häufigkeit der braunen Färbungsvariante des Kuckucks Cuculus canorus in Deutschland. Ornithol Mitt 55:127-131

Carlborg Ö, Haley CS (2004) Epistasis: too often neglected in complex trait studies? Nat Rev Genet 5:618-625

Cramp S (1985) The birds of the Western Palearctic. Vol. IV. Oxford University Press, Oxford

Davies NB, Welbergen JA (2008) Cuckoo-hawk mimicry? An experimental test. Proc R Soc B 275:1817-1822

Dittrich W (1982) About the abundance of the Cuckoo (Cuculus canorus) in northern Bavaria and the recorded proportion of its hepatic colour phase. Vogelwelt 103:188-189

Ferguson-Lees J, Christie D (2001) Raptors of the World. Christo pher Helm, London

Foster MS (1987) Delayed maturation, neoteny, and social system differences in two manakins of the genus Chiroxiphia. Evolution 41:547-558

Galeotti P, Rubolini D, Dunn PO, Fasola M (2003) Colour polymorphism in birds: causes and functions. J Evol Biol 16:635-646

Galván I, Ghanem I, Møller AP (2012) Has removal of excess cysteine led to the evolution of pheomelanin? BioEssay 34:565-568

Galván I, Møller AP (2013) Pheomelanin-based plumage coloration predicts survival rates in birds. Physiol Biochem Zool 86:184-192

Galván I, Solano F (2016) Bird integumentary melanins: biosynthesis, forms, function and evolution. Int J Mol Sci 17:520

Gamer M, Lemon J, Singh IFP (2012) irr: Various Coefficients of Interrater Relia bility and Agreement. $R$ package version 0.84

Gould SJ (1977) Ontogeny and Phylogeny. Harvard University Press, Cambridge

Gray SM, McKinnon JS (2007) Linking color polymorphism maintenance and speciation. Trends Ecol Evol 22:71-79

Gregory RD, Vorisek P, Van Strien A, Meyling AWG, Jiguet F, Fornasari L, Reif J, Chylarecki P, Burfield IJ (2007) Population trends of widespread woodland birds in Europe. Ibis 149:78-97

Griffiths R, Double MC, Orr K, Dawson RJG (1998) A DNA test to sex most birds. Mol Ecol 7:10711075

Heidecke D (1981) Zum Auftreten der rotbraunen Varietät des Kuckucks. Ornithol Rundbr Mecklenburg 24:6-8

Heyder R (1952) Die Vögel des Landes Sachsen. Akademische Verlag Gesellschaft, Leipzig

Hill GE, McGraw KJ (2006) Bird Coloration, vol 2. Function and Evolution. Harvard University Press, Cambridge

Honza M, Šicha V, Procházka P, Ležalová R (2006) Host nest defense against a color-dimorphic brood parasite: great reed warblers (Acrocephalus arundinace us) versus common cuckoos (Cuculus canorus). J Ornithol 147:629-637 
Huxley J (1955) Morphism in birds. Acta Int Congr Ornithol XI:309-328

ImageJ (2018) Image Processing and Analysis in Java. http://rsb.info.nih.gov/ij (accessed 26 March 2018)

Kappers EF, Chakarov N, Krüger O, Mueller AK, Valcu M, Kempenaers B, Both C (2017) Classification and temporal stability of plumage variation in Common Buzzards. Ardea 105:125-136

Karell P, Ahola K, Karstinen T, Valkama J, Brommer JE (2011) Climate change drives microevolution in a wild bird. Nat Commun 2:208

Küpper C, Stocks M, Risse JE, dos Remedios N, Farrell LL, McRae SB, Morgan TC, Karlionova N, Pinchuk P, Verkuil YI, Kitaysky A, Wingfield J, Piersma T, Zeng K, Slate J, Blaxter M, Lank D, Burke T (2016) A supergene determines highly divergent male reproductive morphs in the ruff. Nat Genet 48:79

Lank DB, Smith CM, Hanotte O, Burke T, Cooke F (1995) Genetic polymorphism for alternative mating behaviour in lekking male Ruff Philomachus pugnax. Nature 378:59-62

Lönnberg E (1929) Svenska Få glar. Ivar Baarsen, Stockholm Mann C (2014) Common and Oriental cuckoos: photo guide. Birdwatch 6/2014:45-51 Maumary L, Vallotton L, Kna us P (2007) Die Vögel der Schweiz. Schweizerische Vogelwarte and Nos Oiseaux, Montmollin and Sempach

McGraw KJ, Safran RJ, Wakamatsu K (2005) How feather colour reflects its mela nin content. Funct Ecol 19:816-821

McKinney ML, McNamara K (1991) Heterochrony: The Evolution of O ntogeny. Plenum Press, New York

McKinnon JS, Pierotti ME (2010) Colour polymorphism and correlated characters: genetic mechanisms and evolution. Mol Ecol 19:5101-5125

Noh HJ, Lee JW, Yoo JC (2016) Color morph variation in two brood parasites: common cuckoo and lesser cuckoo. Ornithol Sci 15:109-117

Odom KJ, Hall ML, Riebel K, Omland KE, Langmore NE (2014) Female song is widespread and ancestral in songbirds. Nat Commun 5:3379

Payne RB (1967) Interspecific communication signals in parasitic birds. Am Nat 101:363-375

Phillips PC (2008) Epistasis - the essential role of gene interactions in the structure and evolution of genetic systems. Nat Rev Genet 9:855-867

Quadrelli F (1990) Percentage of "hepatic" Cuckoos, Cuculus canorus, in the low Po Plain. Riv Ital Ornitol 59:313

R Core Team (2016) R: a la nguage and environment for statistical computing. Vienna: R Foundation for Statistical Computing. https://www.R-project.org/

Rankin KJ, McLean CA, Kemp DJ, Stuart-Fox D (2016) The genetic basis of discrete and quantitative colour variation in the polymorphic lizard, Ctenophorus decresii. BMC Evol Biol 16:179

Ringleben H (1958) Ein altes rostrotes Männchen des Kuckucks (Cuculus canorus). J Ornithol 99:375 
Roulin A (2004) The evolution, maintenance and a daptive function of genetic colour polymorphism in birds. Biol Rev 79:815-848

Sackl P (1985) Zum Auftreten der rotbraunen Farbphase beim Kuckuck, Cuculus canorus L., in der mittleren Oststeiermark. Mitt Abt Zool Landesmus Joanneum 34:31-33

Schaanning HTL (1916) Norges Fuglefauna. Cappelen, Kristia nia

Sinervo B, Svensson E (2002) Correlational selection and the evolution of genomic architecture. Heredity 89:329-338

Sinervo B, Zamudio K (2001) The evolution of alternative reproductive strategies: fitness differential, herita bility and genetic correlation between the sexes. J Hered 92:198-205

Thorogood R, Davies NB (2012) Cuckoos combat socially transmitted defenses of reed warbler hosts with a plumage polymorphism. Science 337:578-580

Tischler F (1941) Die Vögel Ostpreussens and seiner Nachbargebiete. I. Königsberg (Pr.) u, Berlin

Trnka A, Grim T (2013) Color plumage polymorphism and predator mimicry in brood parasites. Front Zool 10:25

Trnka A, Trnka M, Grim T (2015) Do rufous common cuckoo females indeed mimic a predator? An experimental test. Biol J Linn Soc 116:134-143

Venables WN, Ripley BD (2002) Modern Applied Statistics with S. Fourth Edition. Springer, New York Voipio P (1953) The hepaticus variety and the juvenile plumage types of the Cuckoo. Ornis Fennica 30:97-117

Wauters LA, Zaninetti M, Tosi G, Bertolino S (2004) Is coat-colour polymorphism in Eurasian red squirrels (Sciurus vulgaris L.) adaptive? Mammalia 68:37-48

Welbergen JA, Davies NB (2011) A parasite in wolf's clothing: hawk mimicry reduces mobbing of cuckoos by hosts. Behav Ecol 22:574-579

Wellenreuther M, Svensson El, Hansson B (2014) Sexual selection and genetic colour polymorphisms in animals. Mol Ecol 23:5398-5414

Witherby HF, Jourdain FCR, Ticehurst NF, Tucker BW (1949) The Handbook of British Birds. HF \& G. Witherby, London 
425 Germany

426 East Prussia

427 Göttingen

$51^{\circ} 33^{\prime} \mathrm{N} 9^{\circ} 56^{\prime} \mathrm{E}$

relatively scarce

$47^{\circ} 45^{\prime} \mathrm{N} 9^{\circ} 01^{\prime} \mathrm{E}$

Mindelsee

Northern Bavaria

Saxony

432 Sleswick-Holsatia

433

Upper Lusatia

434 Entire country

435

436

$438 \quad$ Entire British Isles

439

440

Other countries $52^{\circ} 18^{\prime} \mathrm{N}, 0^{\circ} 17^{\prime} \mathrm{E}$

$<1 *$

scarce
$<30 *$

$<1$

Tischler 1941

Arbeitskreis Göttinger Ornithologen 2007

Heidecke 1981

Löhrl 1979

$66412(4.7-23.5)$

Dittrich 1982

nowhere frequently Heyder 1952

5-10 Berndt et al. 2003

$>300<5$

Becker and Dankhoff 1973

Busche 2003

Thorogood and Davies 2012

Whitherby et al. 1949 


\begin{tabular}{|c|c|c|c|c|c|}
\hline 441 & Finland & & $8^{*}$ & 50 & Voipio 1953 \\
\hline 442 & Italy & & & $1.6-1.8$ & Brichetti and Fracasso 2006 \\
\hline 443 & Norway & & & rarer than grey & Schaanning 1916 \\
\hline 444 & Sweden & & & rarer than grey & Lönnberg 1929 \\
\hline 445 & Switzerland & & & scarce & Maumary et al. 2007 \\
\hline 446 & & & & & \\
\hline 447 & Other sites & & & & \\
\hline 448 & Apaj (Hungary) & $47^{\circ} 09^{\prime} \mathrm{N} 19^{\circ} 05^{\prime} \mathrm{E}$ & $30 *$ & 60 & Honza et al. 2006 \\
\hline 449 & Fürstenfeld (Austria) & $47^{\circ} 03^{\prime} \mathrm{N} 16^{\circ} 05^{\prime} \mathrm{E}$ & 27 & 11.1 & Sackl 1985 \\
\hline 450 & Lužice (Czech Rep.) & $48^{\circ} 50^{\prime} \mathrm{N} 17^{\circ} 04^{\prime} \mathrm{E}$ & $30 *$ & 20 & Honza et al. 2006, this study \\
\hline 451 & North-east Slovenia & & 103 & 6.7 & Bračko 2017 \\
\hline 452 & Po Plain (Italy) & & 115 & 1.77 & Quadrelli 1990 \\
\hline 453 & Štúrovo (Slovakia) & $47^{\circ} 51^{\prime} \mathrm{N} 18^{\circ} 36^{\prime} \mathrm{E}$ & $8^{*}$ & 37.5 & Trnka and Grim 2013 \\
\hline
\end{tabular}


Fig. 1 Proportion of (a) mean plumage colour scores in 41 male and 36 female Cuckoo chicks (1 grey, 2 - medium grey, 3 -intermediate, 4 - medium rufous, 5 - rufous) and (b) proportion of rufous colour at individual feathers from the upper back of 49 male and 38 female Cuckoo chicks

Fig. 2 Mean reflectance spectra of grey and rufous colour on back feathers of (a) 8 Common Cuckoo

461

462

463

464

465 


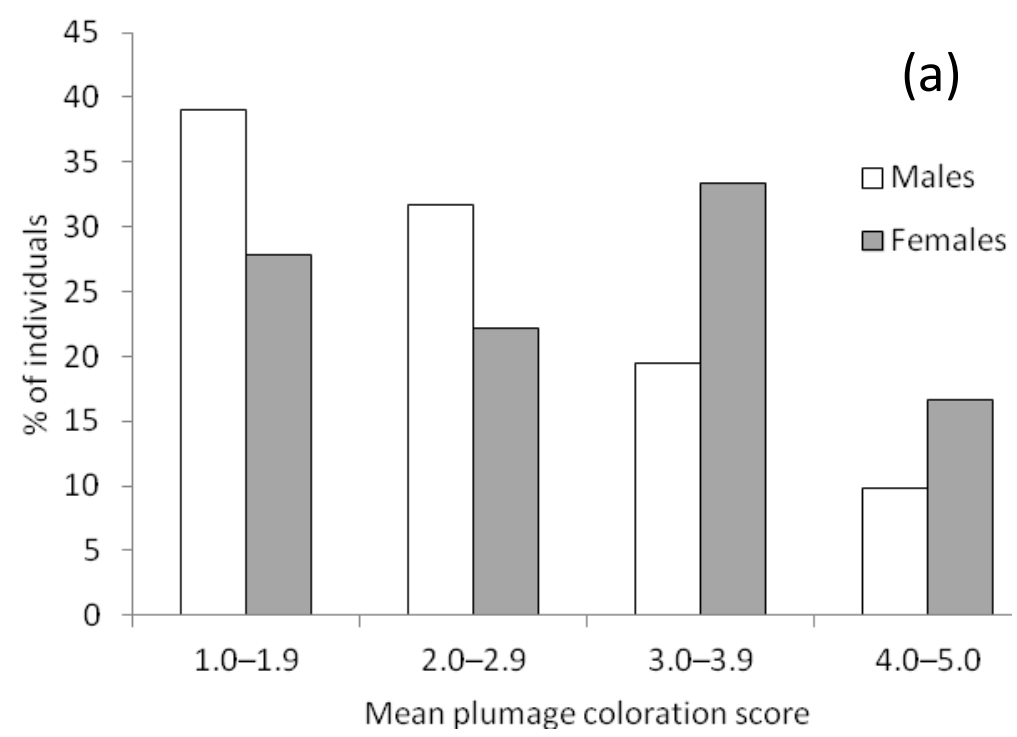

466



467

Fig. 1 




469

$470 \quad$ Fig. 2 